\title{
Anti-Hypertensive Activity of Punica granatum peels Ethyl Acetate Extract on Fludrocortisones Induced Hypertension in Wistar Rats
}

\author{
Rafik Monir ${ }^{1}$, Asmaa S. Abd Elkarim ${ }^{2, *}$, Mohamed Fouad Shalaby ${ }^{3}$, Alsayed Ahmed Zaki ${ }^{4}$, Samah Shabana ${ }^{1}$
}

Rafik Monir ${ }^{1}$, Asmaa S. Abd Elkarim $^{2, *}$, Mohamed Fouad Shalaby ${ }^{3}$, Alsayed Ahmed Zaki ${ }^{4}$, Samah Shabana'

'Faculty of Pharmaceutical Sciences and Drug Manufacturing, Misr University for Science and Technology, MUST, 6th October City, EGYPT.

${ }^{2}$ Chemistry of Tanning Materials and Leather Technology Department, National Research Centre, 33 El Bohouth st. (former EL Tahrir st.)-Dokki-Giza, EGYPT.

${ }^{3}$ Pharmaceutical Sciences Department Pharmacy Program, Batterjee medical college for science and technology, Jeddah, SAUDI ARABIA.

${ }^{4}$ Faculty of Medicine Al-Azhar University, Nasr city, Cairo, EGYPT.

\section{Correspondence}

\section{Asmaa S. Abd Elkarim}

Chemistry of Tanning Materials and Leather Technology Department, National

Research Centre, 33 El Bohouth st. (former

EL Tahrir st.)-Dokki-Giza, EGYPT.

E-mail: asmaa_nrc@yahoo.com

History

- Submission Date: 25-04-2020;

- Review completed: 08-06-2020

- Accepted Date: 22-06-2020

DOI : 10.5530/pj.2020.12.160

Article Available online

http://www.phcogj.com/v12/i5

Copyright

(C) 2020 Phcogj.Com. This is an openaccess article distributed under the terms of the Creative Commons Attribution 4.0 International license.

\begin{abstract}
Pomegranate (Punica granatum Linn.) has several medicinal properties. Pomegranate juice has been reported to be an effective source of high amounts of phyto-constituents with many health and nutritional benefits. This work assessed the possible effect on blood pressure (B.P) and heart rate of $P$. granatum peel ethyl acetate extract (PGE) at a dosage of $400 \mathrm{mg} / \mathrm{kg} /$ day on hypertension-induced fludrocortisone Wistar rats. PGE therapy substantially lowered the B.P of hypertensive rats treated with salt fludrocortisones, but the mean blood pressure and heart rate in normotensive rats were not altered. In isolated aortic strip, the contractile reactions to noradrenalin of PGE-treated hypertensive rats have been substantially reduced. The active fraction was purified by successive chromatographic techniques resulted in isolation of quercetin and ursolic acid, this bioactive mixture induced a significant decrease in the blood pressure of hypertensive rats as compared to hypertensive control rats at a concentration of $10 \mathrm{mg} / \mathrm{kg}$.
\end{abstract}

Key words: Punica granatum, Hypertension, Ursolic acid, Quercetin.

\section{INTRODUCTION}

Chronic increase of peripheral vascular resistance owing to functional (changes in vascular reactivity) and structural (increased wall-to-lumen arteriolar ratio) abnormalities, the main hemodynamic alteration in the established phase of essential human hypertension is considered. ${ }^{1,2}$ The sympathetic central nervous system plays a key role in regulating vascular resistance. Furthermore, an elevated sympathetic control of vascular tone as factors in the development of hypertension was supported by several experimental and clinical evidences. High B.P is also associated with elevated circulating levels of pro-inflammatory cytokines which possible to change both the vascular expression of enzymes for e.g. inducible nitric oxide synthase (iNOS), vascular tone regulation for e.g. iNOS, and vascular tone regulation during this pathology. ${ }^{3,4}$

In fact, increased iNOS vascular action and/ or protein expression were described in the hypertension. ${ }^{5}$ Others have previously studied the function of iNOS-derived NO in responses to vasoconstrictors and endothelium-dependent vasodilators in lipopolysaccharides or interleukin$1 \mathrm{~b}$ stimulated arteries. $^{6-8}$ Oxidative stress can influence the vascular reactivity through various mechanisms. As second messengers, reactive oxygen species activate multiple signaling molecules and act a significant position in vascular physiopathology. ${ }^{910}$ Various sources of superoxide anion $\left(\mathrm{O}_{2}{ }^{-}\right)$were characterized within vessels. $\mathrm{O}_{2}{ }^{-}$ can be produced in different conditions, including xanthine oxidase, uncoupled NOS and COX. However, it is well known at the vascular level that the key source of $\mathrm{O}_{2}-{ }^{11}$ In the present study, the animal hypertension model shares several characteristics that are similar to human hypertension. That most of these methods were constructed using etiological factors that are assumed to be responsible for human hypertension such as excessive salt intake, renin angiotensin-aldosterone (RAAS) hyperactivity. Additionally, there is enhanced secretion of the vasopressin and altered (RAAS) activity resulting in increased sympathetic activity. ${ }^{12}$ Side-effects from antihypertensive medications have encouraged researchers to find novelhypotensive drugs in metabolites or extracts from edible and medicinal plants to control hypertension and that cause less side effects. ${ }^{13}$

\section{MATERIALS AND METHODS}

\section{Preparation of Pomegranate (Punica granatum Linn.) extract (PGE)}

Pomegranate fruits $(3 \mathrm{~kg})$ were purchased from the local market in Abhur, Jeddah, KSA. The fruits were cleaned, shadow dried and stored. The peel and the seed powders were extracted with $70 \%$ ethanol for one week concentrated under vacuum at $60^{\circ} \mathrm{C}$ and then dried. Vacuum-dried ethanolic extract $(800 \mathrm{~g})$ was macerated in ethyl acetate in the solvent: solute ratio of 3: 1 for $48 \mathrm{~h}$ with frequent shaking. The ethyl acetate fraction was dried under vacuum using rotary evaporator IKA- RV10, USA.

Isolation of bioactive compounds of active fraction

Vacuum-dried ethyl acetate extract (150 g) was chromatographed on Silica gel 60 using gradient 
elution of mobile phase ( $n$-hexane: acetone). Active fraction which eluted with ( $n$-hexane: acetone) (8:2) was purified by combination of column chromatography on silica gel G-60, Chromatorex OD successively to yield active compounds $\mathbf{1 , 2}$ which were identified as ursolic acid and quercetin, respectively.

\section{Animals}

Male albino Wistar rats 100-150 gm were used. The study was conducted according to the National Institutes of Health guidelines for the care and use of laboratory animals. All animal care and experimental procedures were carried out with the ethics approval of the local regulatory authority. The animals were kept at room temperature with a $12 \mathrm{~h} / 12 \mathrm{~h}$ dark /light cycle, which allowed us to perform experiments in the active phase of the animals. Rats were habituated to laboratory conditions. Rats received a standard diet and water.

\section{Drugs and chemicals}

PGE was prepared from peels and seeds of P.granatum. Noradrenalin and Fludrocortisone acetate were purchased by Sigma-Aldrich, USA. All other chemicals used in the study were of analytical grade. PGE were suspended in deionized water and administered orally.

\section{Mineralocorticoid induced hypertension}

Groups of rats were kept on a diet high in sodium chloride and drinking water was replaced by $2 \%$ sodium chloride solution. After they attain a weight of about $250 \mathrm{gm}$, they were given fludrocortisones dissolved in sesame oil at dose of $10 \mathrm{mg} / \mathrm{kg}$ once daily for 3 weeks. ${ }^{14}$

\section{Hypotensive activity in normotensive rats}

Normotensive rats of either sex were randomly assigned into 3 groups $(\mathrm{n}=5)$. Group 1 represented normal control, group 2 and 3 received 200 and $400 \mathrm{mg} / \mathrm{kg}$ p.o. of PGE, respectively. Basal blood pressure and heart rates were measured at $0,2,4$ and $6 \mathrm{~h}$ using non-invasive blood pressure recorder apparatus (Ugo basile instruments, Varese, ITALY). Each rat was placed in restrainer and appropriate cuff with sensor was mounted on its tail and warmed to about $33-35^{\circ} \mathrm{C}$. The tail cuff was inflated to a pressure above $200 \mathrm{mmHg}$, systolic blood pressure; diastolic blood pressure and heart rate were measured directly by the tail cuff and pulse sensor. ${ }^{15}$

\section{Antihypertensive activity in hypertensive rats}

Three groups $(n=5)$ of Hypertensive rats $(250 \pm 10 \mathrm{gm})$ were treated orally once daily with deionized water, $10 \mathrm{ml} / \mathrm{kg}$ (control), PGE 200 $\mathrm{mg} / \mathrm{kg}$ and PGE $400 \mathrm{mg} / \mathrm{kg}$ for three weeks. The systolic blood pressure and heart rate were measured by non-invasive blood pressure recorder apparatus before and after treatment. The rats were initially trained for blood pressure measurement on at least three separate occasions to establish a baseline blood pressure.

\section{Vascular reactivity experiments}

Vascular reactivity was studied in aortic segments by isometric tension. ${ }^{16}$ Briefly, two parallel stainless steel pins were introduced through the lumen of the segments: one was fixed to the organ bath wall and the other one was connected to a force transducer (Ugo basile, Italy), which in turn was connected to an amplifier. Segments were incubated in an organ bath containing $25 \mathrm{ml}$ of Krebs-Henseleit solution at $37 \pm 0.5$ ${ }^{\circ} \mathrm{C}$, continuously bubbled with a $95 \% \mathrm{O} 2-5 \% \mathrm{CO} 2$ mixture (pH 7.4). An optimal resting tension of $1.5 \mathrm{~g}$ was applied to all aortic segment. ${ }^{17}$ This tension was adjusted every 15 min during a 60 -min equilibration period before adding drugs. The vessel rings were equilibrated for 1 hour with the tension of $2.0 \mathrm{~g}$ and pre-contracted with $\mathrm{KCl}(60 \mathrm{mM})$ to produce the maximal KCL-induced contractile plateau. Subsequently the cumulative dose-response curve for noradrenaline (NA) $\left(10^{-10}\right.$ $\left.10^{-5} \mathrm{M}\right)$ was obtained. The values of the NA-induced contraction were expressed as a percentage of maximal contraction induced by $\mathrm{KCl}$. During 2 hours of stabilization the tissue was washed every 15 minutes. The dose response curve of nor-adrenalin $\left(8.47 \times 10^{-7}\right.$ to $\left.1.73 \times 10^{-4}\right)$ was studied on the isolated aortic strips of hypertensive rats and hypertensive rats treated with VAD. Contractile response to cumulative addition of agonist was recorded isometrically using Ugo basile transducer. Complete cumulative dose-response curves to NE were successively obtained at $30 \mathrm{~min}$ intervals in the absence and presence of the studied compound added $5 \mathrm{~min}$ before the second curve. Developed tension was plotted versus the log of NE concentration and concentration of $\mathrm{NE}$ producing half-maximal contraction was estimated graphically. ${ }^{18}$

\section{Data analysis and statistics}

Results are expressed as mean \pm s.e.m. of the number of rats indicated; differences were analyzed using Student's t-test. $P>0.05$ was considered as statistically significant. Vasoconstrictor responses induced by Noradrenalin were expressed as a percentage of the tone generated by $75 \mathrm{mM} \mathrm{KCl}$. Straight lines (log dose response curves) was drawn by linear regression.

\section{RESULTS}

\section{Hypotensive activity in normotensive rats}

In normotensive rats, baseline values of systolic blood pressure and $\mathrm{HR}$ were $(118 \pm 1) \mathrm{mmHg}$ and $(376 \pm 10) \mathrm{bpm}$, respectively. Both of the used PGE at doses of $200 \mathrm{mg} / \mathrm{kg}$ and $400 \mathrm{mg} / \mathrm{kg}$ displayed no major hypotensive impact and did not affect HR on normotensive rats with respect to rats taking vehicle-only (Tables 1 and 2).

\section{Anti-hypertensive activity}

After 3 weeks of administration, oral fludrocortisone administration once daily triggered a substantial increase in blood pressure. Everyday oral administration of the various PGE doses led to a variable reduction in B.P. After 3 weeks of treatment, PGE at a dose of $200 \mathrm{mg} / \mathrm{kg}$ and $400 \mathrm{mg} / \mathrm{kg}$ developed substantial $(\mathrm{p}>0.05)$ antihypertensive effect (Table 3).

At a dose of $200 \mathrm{mg} / \mathrm{kg}$ PGE showed a marked drop in heart rate at week 2 and week 3. At high dose ( $400 \mathrm{mg} / \mathrm{kg}$ ) PGE reported a substantial decrease $(p>0,05)$ in the heart rate of hypertensive rats at the end of the third week compared to the control group (Table 4).

Table 1: Effect of PGE on the systolic blood pressure of normotensive rats.

\begin{tabular}{cccc}
\hline & \multicolumn{2}{c}{ Normotensive rats $(\mathrm{SBP} \mathrm{mmHg} \pm \mathrm{SEM}$ ) } \\
\cline { 3 - 4 } Time & $\begin{array}{c}\text { Normal control } \\
\text { group }\end{array}$ & $\mathbf{2 0 0 \mathrm { mg } / \mathrm { kg }}$ & $\mathbf{4 0 0 \mathrm { mg } / \mathrm { kg }}$ \\
\cline { 3 - 4 } $0 \mathrm{hr}$ & $126 \pm 1.11$ & $118 \pm 1.08$ & $123 \pm 1.02$ \\
$2 \mathrm{hr}$ & $116 \pm 1.09$ & $115 \pm 1.10$ & $115 \pm 1.18$ \\
$4 \mathrm{hr}$ & $124 \pm 1.10$ & $121 \pm 0.99$ & $117 \pm 0.77$ \\
$6 \mathrm{hr}$ & $122 \pm 1.19$ & $112 \pm 0.87$ & $122 \pm 0.81$ \\
\hline
\end{tabular}

SBP: Systolic blood pressure, all values are mean of 5 observations + SE.

Table 2: Effect of PGE on the heart rate of normotensive rats.

\begin{tabular}{|c|c|c|c|}
\hline \multicolumn{4}{|c|}{ Normotensive rats (Heart beats $/ \mathrm{min} \pm \mathrm{SEM}$ ) } \\
\hline \multirow{2}{*}{ Time } & \multirow{2}{*}{$\begin{array}{l}\text { Normal control } \\
\text { group }\end{array}$} & \multicolumn{2}{|c|}{ Treatment } \\
\hline & & $200 \mathrm{mg} / \mathrm{kg}$ & $400 \mathrm{mg} / \mathrm{kg}$ \\
\hline $0 \mathrm{hr}$ & $379 \pm 3.51$ & $385 \pm 2.99$ & $372 \pm 3.22$ \\
\hline $2 \mathrm{hr}$ & $395 \pm 3.43$ & $371 \pm 3.01$ & $420 \pm 3.84$ \\
\hline $4 \mathrm{hr}$ & $389 \pm 3.85$ & $451 \pm 3.21$ & $397 \pm 3.44$ \\
\hline $6 \mathrm{hr}$ & $392 \pm 3.75$ & $402 \pm 3.88$ & $375 \pm 3.72$ \\
\hline
\end{tabular}

All values are mean of 5 observations + SE. 


\section{Antihypertensive activity of isolated fractions}

Non polar fraction at dose of $10 \mathrm{mg} / \mathrm{kg}$ induced a significant decrease in the blood pressure of hypertensive rats as compared to hypertensive control rats while polar fractions showed no change in the blood pressure of hypertensive rats at the same dose (Figure 1 \& Table 4).

\section{Contractile response of vascular ring to NA}

The vascular dysfunction is associated with increased vasoconstriction and a reduced diastolic function. We are therefore interested in deciding where the vascular where the vascular feature switches to a physiological modulator by detecting the vascular reactivity of the aortic rings, noradrenaline (NA). In isolated aortic rings, the cumulatively added NA (10-10-10-5 M) caused concentration-dependent contractile responses. We found that the group treated with DOCA there significantly increased, PGE treatment reduced the vasoconstrictive effect than the treatred group (Figure 1). In addition, the PGE treated group's contractile responsivity to NA was significantly lower than the control group (Figure 1). PGE treatment ( $400 \mathrm{mg}$ ) significantly changed the dose-response curve of noradrenalin in isolated aortic strips to the right, As compared to the DOCA salt-treated hypertensive animals dose-response curve.

\section{Identification of active compounds 1 and 2}

Compound 1 was obtained as white powder that showed purple color on TLC after spraying with vanillin $\mathrm{H}_{2} \mathrm{SO}_{4}$. The ${ }^{1} \mathrm{H}$ and ${ }^{13} \mathrm{C}$ NMR spectral data were given in Table 6 The ${ }^{1} \mathrm{Hand}{ }^{13} \mathrm{C}$ NMR spectra of compound $\mathbf{1}$ (Figures 2 and 3) exhibited signals of an olefinic proton at $\delta_{\mathrm{H}} 5.08$ $\left(\mathrm{H}-12, \mathrm{~s} ; \delta_{\mathrm{C}} 126.19\right)$, seven methyl signals at $\delta_{\mathrm{H}} 0.85\left(3 \mathrm{H}-23, \mathrm{~s} ; \delta_{\mathrm{C}} 28.75\right)$, $\delta_{\mathrm{H}} 0.84\left(3 \mathrm{H}-24, \mathrm{~s} ; \delta_{\mathrm{C}} 16.32\right), \delta_{\mathrm{H}} 0.64\left(3 \mathrm{H}-25, \mathrm{~s} ; \delta_{\mathrm{C}} 15.89\right), \delta_{\mathrm{H}} 0.71(3 \mathrm{H}-$ $\left.26, \mathrm{~s} ; \delta_{\mathrm{C}} 17.50\right), \delta_{\mathrm{H}} 0.99\left(3 \mathrm{H}-27, \mathrm{~s} ; \delta_{\mathrm{C}} 23.95\right), \delta_{\mathrm{H}} 0.75(3 \mathrm{H}-29, \mathrm{~d} . J=6.8$ $\left.\mathrm{Hz} ; \delta_{\mathrm{C}} 17.65\right)$ and $\delta_{\mathrm{H}} 0.82\left(3 \mathrm{H}-30, \mathrm{~d} . J=6.0 \mathrm{~Hz} ; \delta_{\mathrm{C}} 21.43\right)$, nine methylene signals at $\delta_{\mathrm{H}} 1.50\left(2 \mathrm{H}-1, \mathrm{~m} ; \delta_{\mathrm{C}} 39.45\right), \delta_{\mathrm{H}} 1.41\left(2 \mathrm{H}-2, \mathrm{~m} ; \delta_{\mathrm{C}} 28.23\right), \delta_{\mathrm{H}}$ $1.41\left(2 \mathrm{H}-6, \mathrm{~m} ; \delta_{\mathrm{C}} 19.02\right),\left(\delta_{\mathrm{H}} 1.80\left(\mathrm{H}-7_{\mathrm{b}}, \mathrm{m}\right)\right.$ and $\delta_{\mathrm{H}} 1.28\left(\mathrm{H}-7_{\mathrm{a}}, \mathrm{m} ; \delta_{\mathrm{C}} 33.92\right)$, $\delta_{\mathrm{H}} 1.80\left(2 \mathrm{H}-11, \mathrm{~m} ; \delta_{\mathrm{C}} 23.89\right), \delta_{\mathrm{H}} 1.41\left(2 \mathrm{H}-15, \mathrm{~m} ; \delta_{\mathrm{C}} 28.69\right), \delta_{\mathrm{H}} 1.50(2 \mathrm{H}-$ $\left.16, \mathrm{~m} ; \delta_{\mathrm{C}} 24.95\right), \delta_{\mathrm{H}} 1.41\left(2 \mathrm{H}-21, \mathrm{~m} ; \delta_{\mathrm{C}} 31.35\right)$ and $\delta_{\mathrm{H}} 1.50(2 \mathrm{H}-22, \mathrm{~m}$; $\left.\delta_{\mathrm{C}} 37.56\right)$,five methine signals at $\delta_{\mathrm{H}} 0.66\left(\mathrm{H}-5, \mathrm{~d} . J=5.6 \mathrm{~Hz} ; \delta_{\mathrm{C}} 56.14\right), \delta_{\mathrm{H}}$ $1.41\left(\mathrm{H}-9, \mathrm{~m} ; \delta_{\mathrm{C}} 48.22\right), \delta_{\mathrm{H}} 2.09\left(\mathrm{H}-18\right.$, d. $\left.J=12.8 ; \delta_{\mathrm{C}} 53.83\right), \delta_{\mathrm{H}} 1.50(\mathrm{H}-$ $\left.19, \mathrm{~m} ; \delta_{\mathrm{C}} 39.85\right)$ and $\delta_{\mathrm{H}} 1.41\left(\mathrm{H}-20, \mathrm{~m} ; \delta_{\mathrm{C}} 39.80\right)$ and one oxygenated methine signal at $\delta_{\mathrm{H}} 3.00\left(\mathrm{H}-3, \mathrm{dd} . J=4.8,10.8 \mathrm{~Hz} ; \delta_{\mathrm{C}} 78.55\right)$. In addition, the ${ }^{13} \mathrm{C}$-NMR spectrum showed signals that w14ere allocated to one olefinic quaternary carbon $\left(\mathrm{C}-13, \delta_{\mathrm{C}} 139.26\right)$, one carboxylic acid $(\mathrm{C}-28$, $\left.\delta_{\mathrm{C}} 178.54\right)$ and five quaternary carbons $\left(\mathrm{C}-4, \delta_{\mathrm{C}} 32.74\right),\left(\mathrm{C}-8, \delta_{\mathrm{C}} 40.34\right)$, $\left(\mathrm{C}-10, \delta_{\mathrm{C}} 37.71\right),\left(\mathrm{C}-14, \delta_{\mathrm{C}} 42.82\right)$ and $\left(\mathrm{C}-17, \delta_{\mathrm{C}} 48.43\right)$.

Table 3: Effect of PGE on systolic BP of hypertensive rats on continuous therapy for 21 days.

\begin{tabular}{ccccc}
\hline \multirow{5}{*}{ Hreatment } & \multicolumn{5}{c}{ Dypertensive rats (SBP \pm SEM) } \\
\cline { 2 - 5 } & 0 & 7 & 14 & 21 \\
\hline Normal control & $110.50 \pm 3.64$ & $110.83 \pm 3.38$ & $90.50 \pm 0.81$ & $112.30 \pm 1.89$ \\
Hypertensive control & $145.16 \pm 0.79^{*}$ & $144.83 \pm 1.47^{*}$ & $155.40 \pm 1.41^{*}$ & $140.11 \pm 1.63^{*}$ \\
PGE $200 \mathrm{mg} / \mathrm{kg}$ & $143.50 \pm 1.31$ & $152.40 \pm 1.89$ & $131.20 \pm 0.89^{* *}$ & $123.90 \pm 1.29^{* *}$ \\
PGE 400mg/kg & $146.10 \pm 1.38$ & $143.20 \pm 0.83$ & $128.40 \pm 1.12^{* *}$ & $119.26 \pm 0.89^{* *}$ \\
\hline
\end{tabular}

SBP: Systolic Blood Pressure, All values are mean of 5 observations $+\mathrm{SE},{ }^{*} \mathrm{P}<0.05$ compared to normal control group, ${ }^{* *} \mathrm{P}<0.05$ compared to hypertensive control group.

Table 4: Effect of PGE on heart rate of hypertensive rats on continuous therapy for 21 days.

\begin{tabular}{ccccc}
\hline & \multicolumn{4}{c}{ Hypertensive rats (Heart beats/min \pm SEM) } \\
\cline { 2 - 5 } Treatment & 0 & 7 & 14 & 21 \\
\hline Normal control & $411.33 \pm 3.64$ & $387.3 \pm 3.45$ & $378.7 \pm 3.64$ & $418.14 \pm 3.89$ \\
Hypertensive control & $445.16 \pm 2.79$ & $444.73 \pm 4.47^{*}$ & $455.10 \pm 4.41^{*}$ & $440.11 \pm 3.63$ \\
PGE $200 \mathrm{mg} / \mathrm{kg}$ & $443.50 \pm 3.31$ & $452.30 \pm 3.89$ & $431.20 \pm 3.89$ & $423.90 \pm 3.29$ \\
PGE 400mg/kg & $446.40 \pm 3.38$ & $443.40 \pm 3.83$ & $435.40 \pm 1.12$ & $376.25 \pm 2.89^{* *}$ \\
\hline
\end{tabular}

${ }^{*} \mathrm{P}<0.05$ compared to Normal control group, ${ }^{* *} \mathrm{P}<0.05$ compared to hypertensive control group, all values are mean of 5 observations $+\mathrm{SE}$

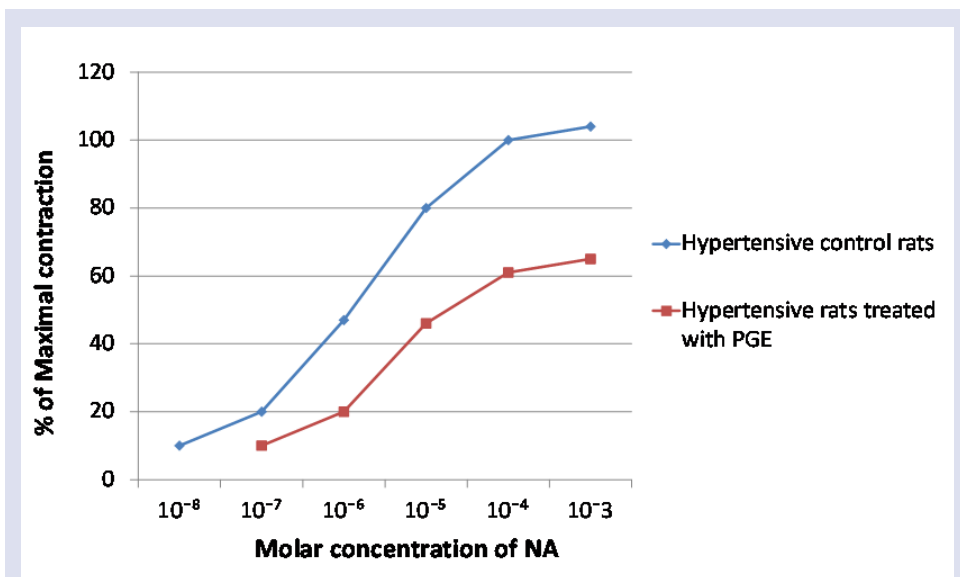

Figure 1: Cumulative dose-response curve to noradrenaline in aortic strips of rats made hypertensive by DOCA (hypertensive control rats) and hypertensive rats treated with PGE $(400 \mathrm{mg} / \mathrm{kg}) . P<0.05$ compared to hypertensive control group. 

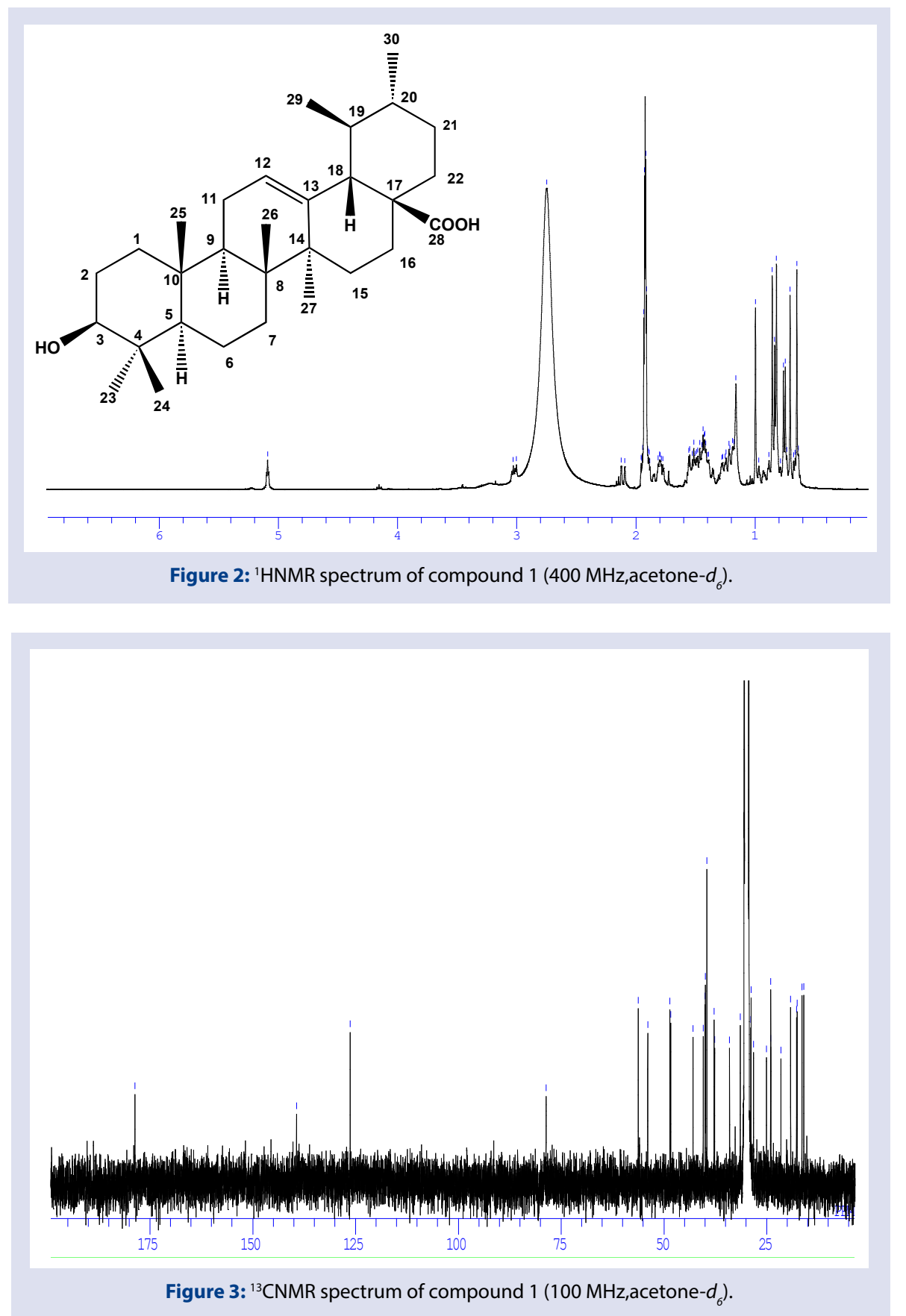

On the basis of spectroscopic information, compound 1 was identified as $3 \beta$-hydroxyurs-12-en 28oic acid (ursolic acid).

Compound 2 was isolated as yellow needles and it showed blue color with $\mathrm{FeCl}_{3}$ on TLC. It confirmed by ${ }^{1} \mathrm{H}$ and ${ }^{13} \mathrm{C}$ NMR data (Table 7 ) to be quercetin. The ${ }^{1} \mathrm{H}$ and ${ }^{13} \mathrm{C}$ NMR spectra of compound 2 (Figure 4 and 5) showed signals with good agreement with those previosly reported.

\section{DISCUSSION}

This study reveals that in experimentally induced hypertensive models, PGE has a major antihypertensive effect. DOCA-induced hypertension is due to the sodium and water retention. The altered membrane permeability in the DOCA salt-treated hypertensive models has also been shown to cause an abnormal cation turnover. Such irregular loss of cation leads to vasoconstriction and eventually to an elevated B.P. In DOCA salt-treated hypertensive rats, the enhanced vascular sensitivity to noradrenaline is also attributed to enhance mobilization of $\mathrm{Ca}$ ion into the vascular smooth muscle. ${ }^{19}$ Changes in voltage operating calcium channels or calcium permeability may be the main reasons for maintaining hypertension in the salt-treated hypertensive model DOCA. ${ }^{20}$ Current in vivo and in vitro studies have shown that DOCA salt-treated hypertensive models have improved vascular reactivity to noradrenaline and adrenaline.

Both 10(-7) M PE and 10(-6) M ACh significantly increased K (+) uptake in endothelium-intact aorta versus control (121 \% PE, 117 \% ACh). ${ }^{21}$ Reducing VAD vascular reactivity in DOCA salt-treated hypertensive rats indicates that the sensitivity of the adrenoceptor to either adrenaline or adrenaline is altered. Focusing on the hypertension mechanism in the DOCA salt-treated hypertensive models, it is indicated that the antihypertensive effects of PGE may led to its alteration in cation transport across the cell membrane. It was reported 
Table 5: The nonpolar paraffin oil fraction of the peels of $P$.granatum induced a significant decrease in the blood pressure of hypertensive rats as compared to hypertensive control rats. The polar aqueous fractions of peels of $P$. granatum showed no change in the blood pressure of hypertensive rats (Figure 1).

\begin{tabular}{|c|c|c|c|c|}
\hline \multicolumn{5}{|c|}{ Hypertensive rats (systolic BP \pm SEM } \\
\hline \multirow{2}{*}{ Treatment } & \multicolumn{4}{|c|}{ Days } \\
\hline & 0 & 7 & 14 & 21 \\
\hline Normal control & $110.50 \pm 3.64$ & $110.83 \pm 3.38$ & $90.50 \pm 0.81$ & $112.30 \pm 1.89$ \\
\hline Hypertensive control & $145.16 \pm 0.79$ & $144.83 \pm 1.47$ & $155.40 \pm 1.41$ & $140.11 \pm 1.63$ \\
\hline Polar aqueous fraction ( $10 \mathrm{mg} / \mathrm{kg}$ po $)$ & $143.50 \pm 1.31$ & $146.40 \pm 1.89$ & $141.20 \pm 0.89$ & $136.90 \pm 1.29$ \\
\hline Nonpolar paraffin oil fraction $(10 \mathrm{mg} / \mathrm{kg}$ po $)$ & $146.10 \pm 1.38$ & $136.20 \pm 0.83$ & $128.40 \pm 1.12$ & $123.26 \pm 0.89$ \\
\hline
\end{tabular}

Table 6: ${ }^{1} \mathrm{H}$ NMR and ${ }^{13}$ CNMRdata of compound 1.

\begin{tabular}{ccl}
\hline position & $\Delta \mathrm{c}$ & $\boldsymbol{\delta}_{\mathrm{H}}$ (integral, mult., $\mathrm{J} \mathrm{H}_{\mathrm{z}}$ ) \\
\hline 1 & 39.45 & $1.50(2 \mathrm{H}, \mathrm{m})$ \\
2 & 28.23 & $1.41(2 \mathrm{H}, \mathrm{m})$ \\
3 & 78.55 & $3.00(1 \mathrm{H}, \mathrm{dd} . J=4.8,10.8 \mathrm{~Hz})$ \\
4 & 32.74 & - \\
5 & 56.14 & $0.66(1 \mathrm{H}, \mathrm{d} . J=5.6 \mathrm{~Hz})$ \\
6 & 19.02 & $1.41(2 \mathrm{H}, \mathrm{m})$ \\
7 & 33.92 & $1.80(1 \mathrm{H}, \mathrm{m})-1.28\left(1 \mathrm{H}_{\mathrm{a}}, \mathrm{m}\right)$ \\
8 & 40.34 & - \\
9 & 48.22 & $1.41(1 \mathrm{H}, \mathrm{m})$ \\
10 & 37.71 & - \\
11 & 23.89 & $1.80(2 \mathrm{H}, \mathrm{m})$ \\
12 & 126.19 & $5.08(1 \mathrm{H}, \mathrm{s})$ \\
13 & 139.26 & - \\
14 & 42.82 & - \\
15 & 28.69 & $1.41(2 \mathrm{H}, \mathrm{m})$ \\
16 & 24.95 & $1.50(2 \mathrm{H}, \mathrm{m})$ \\
17 & 48.43 & - \\
18 & 53.83 & $2.09(1 \mathrm{H}, \mathrm{d} . J=12.8 \mathrm{~Hz})$ \\
19 & 39.85 & $1.50(1 \mathrm{H}, \mathrm{m})$ \\
20 & 39.80 & $1.41(1 \mathrm{H}, \mathrm{m})$ \\
21 & 31.35 & $1.41(2 \mathrm{H}, \mathrm{m})$ \\
22 & 28.69 & $1.50(2 \mathrm{H}, \mathrm{m})$ \\
23 & 28.75 & $0.85(3 \mathrm{H}, \mathrm{s})$ \\
24 & 16.32 & $0.84(3 \mathrm{H}, \mathrm{s})$ \\
25 & 15.89 & $0.64(3 \mathrm{H}, \mathrm{s})$ \\
26 & 17.50 & $0.71(3 \mathrm{H}, \mathrm{s})$ \\
27 & 23.95 & $0.99(3 \mathrm{H}, \mathrm{s})$ \\
28 & 178.54 & - \\
29 & 17.65 & $0.75(3 \mathrm{H}, \mathrm{d} . J=6.8 \mathrm{~Hz})$ \\
30 & 21.43 & $0.82(3 \mathrm{H}, \mathrm{d} . J=6.0 \mathrm{~Hz})$ \\
\hline & & \\
\hline & &
\end{tabular}

Taken in acetone- $d_{6}$ at $400 \mathrm{MHz}$ for ${ }^{1} \mathrm{H}$ NMR and at $100 \mathrm{MHz}$ for ${ }^{13} \mathrm{C}$ NMR.

Table 7: ${ }^{1}$ H NMR and ${ }^{13}$ C NMR data of compound 2.

\begin{tabular}{|c|c|c|}
\hline Position & $\Delta \mathrm{c}$ & $\delta_{H}$ (integral, mult. $\mathrm{J} \mathrm{H}_{\mathrm{z}}$ ) \\
\hline 2 & 147.94 & \\
\hline 3 & 136.34 & \\
\hline 4 & 176.15 & \\
\hline 5 & 161.91 & \\
\hline 6 & 98.74 & $6.24(1 \mathrm{H}, \mathrm{d} . J=1.6 \mathrm{~Hz})$ \\
\hline 7 & 164.57 & \\
\hline 8 & 94.05 & $6.52(1 \mathrm{H}, \mathrm{d} . J=1.6 \mathrm{~Hz})$ \\
\hline 9 & 157.35 & \\
\hline 10 & 103.72 & \\
\hline 1 & 123.40 & \\
\hline 2 & 115.82 & $7.80(1 \mathrm{H}, \mathrm{d} . J=2.0 \mathrm{~Hz})$ \\
\hline 3 & 145.41 & \\
\hline $4^{\prime}$ & 146.52 & \\
\hline $5^{\prime}$ & 115.36 & $6.96(1 \mathrm{H}, \mathrm{d} . J=8.8 \mathrm{~Hz})$ \\
\hline $6^{\prime}$ & 121.04 & $7.67(1 \mathrm{H}, \mathrm{dd} . J=8.8,2.0 \mathrm{~Hz})$ \\
\hline
\end{tabular}

Taken in acetone- $d_{6}$ at $400 \mathrm{MHz}$ for ${ }^{1} \mathrm{H}-\mathrm{NMR}$ and at $100 \mathrm{MHz}$ for ${ }^{13} \mathrm{C}-\mathrm{NMR}$. 

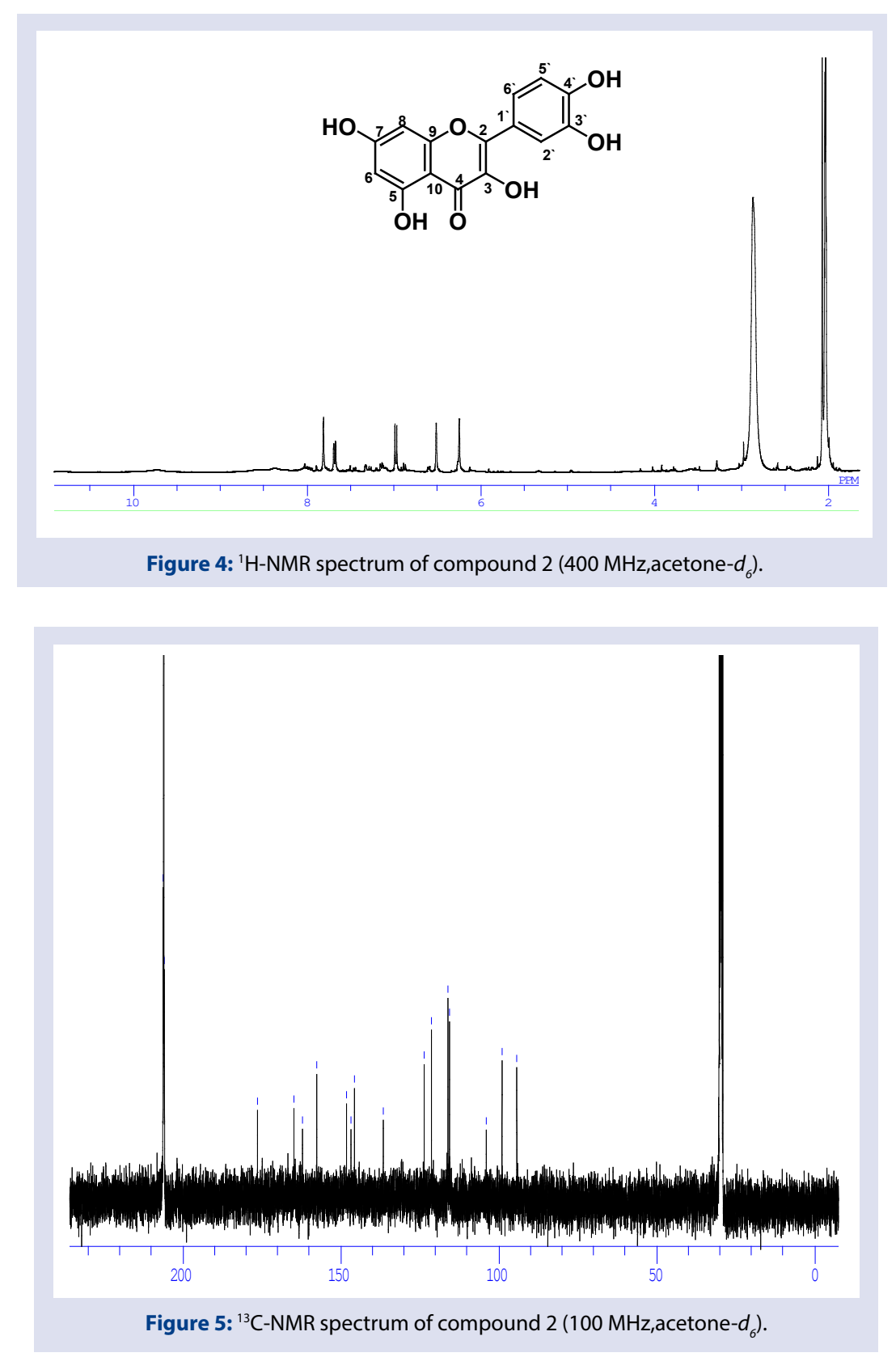

that quercetin reduces the raised blood pressure, due to its antioxidant properties.2. A number of proposed mechanisms may be responsible for the observed decrease in blood pressure including decreased oxidative stress, inhibition of angiotensin-converting enzyme activity, enhanced endothelial function, direct action on the smooth vascular muscle, and/ or modulation in cell signaling and gene expression. Even if proof exists in vitro and in vivo to help and refute any possibility, Although there is evidence in vitro and in vivo to support and disprove every possibility, quercetin is likely to influence multiple targets through a combination of known and yet undiscovered mechanisms. ${ }^{23}$ Mechanistically, the protective effect of ursolic acid is indeed by restoring the intracellular redox state and by inducing an antiapoptotic protein expression $\mathrm{MCl}^{-1}$, The striking finding that ursolic acid has anti-apoptotic and antioxidant activity against ER stress-associated myocardial damage indicates that ursolic acid supplementation may be a possible strategy for mitigating the harmful effects of heat stress in cardiomyocytes. ${ }^{24}$ Despite antihypertensive activity of ursolic acid was not reported this study showed its synergistic action for antihypertensive activity of quercetin compared to previous studies.

\section{CONCLUSION}

The bioactive mixture (ursolic acid and quercetin) induced a significant decrease in the blood pressure of hypertensive rats as compared to hypertensive control rats at a concentration of $10 \mathrm{mg} / \mathrm{kg}$.

\section{REFERENCES}

1. Estato $V$, Araújo $C V$, Bousquet $P$, Tibiriçá E. Effects of centrally acting antihypertensive drugs on the microcirculation of spontaneously hypertensive rats. Brazilian Journal of Medical and Biological Research. 2004;37(10):1541-9.

2. Mayet J, Hughes A. Cardiac and vascular pathophysiology in hypertension. Heart. 2003;89(9):1104-9.

3. Penna, Guilherme A, Garbero, Rodrigo F, Neves, Mario F, et al. Treatment of essential hypertension does not normalize capillary rarefaction. Clinics. 2008;63(5):613-8.

4. Savoia C, Schiffrin EL. Inflammation in hypertension. Current Opinion in Nephrology and Hypertension. 2006;15(2):152-8.

5. Briones AM, Alonso MJ, Marín J, Balfagón G, Salaices M. Influence of hypertension on nitric oxide synthase expression and vascular effects of lipopolysaccharide in rat mesenteric arteries. British Journal of Pharmacology 2000;131(2):185-94. 
6. Hernanz R, Alonso MJ, Briones AM, Vila E, Simonsen U, et al. Mechanisms involved in the early increase of serotonin contraction evoked by endotoxin in rat middle cerebral arteries. British Journal of Pharmacology. 2003;140(4):67180 .

7. Vopa, Lad B, Tomlinson JA, Francis S, Ahluwalia A. Autoregulatory role of endothelium-derived nitric oxide (NO) on lipopolysaccharide-induced vascular inducible NO synthase expression and function. Journal of Biological Chemistry. 2005;280(8):7236-43

8. Jiménez-Altayó F, Briones AM, Giraldo J, Planas AM, Salaices M, et al. Increased superoxide anion production by interleukin-1 $\beta$ impairs nitric oxide-mediated relaxation in resistance arteries. Journal of pharmacology and Experimental Therapeutics. 2006;316(1):42-52.

9. ParaviciniTM, Touyz RM. Redox signaling in hypertension. Cardiovasc Research. 2006;71(2):247-58.

10. Vaziri ND, Rodríguez-Iturbe B. Mechanisms of disease: oxidative stress and inflammation in the pathogenesis of hypertension. Nature Clinical Practice Nephrology. 2006;2(10):582-93.

11. Chamseddine AH, Miller FJ. Jr Gp91phox contributes to NADPH oxidase activity in aortic fibroblasts but not smooth muscle cells. American Journal of Physiology-Heart and Circulatory. 2003;285(6):H2284-9.

12. Badyal DK, lata $\mathrm{H}$, Dadhich. Animal models of Hypertension and effect of drugs. Indian Journal of Pharmacology. 2006;35:349-62.

13. Ahmadi BB, Bahmani M, Tajeddini P, Kopaei RM, Naghdi N. An ethnobotanical study of medicinal plants administered for the treatment of hypertension. Journal of Renal Injury Prevention. 2006;5(3):123-8.

14. Hensen J, Oelkers W. Mineralocorticoid-induced hypertension. Medizinische Klinic Munich. 1997;92(5):273-8.

15. Mishra, Ravinesh, Siddiqui, Anees A Hussain, ASIF et al. Synthesis, characterization and hypertensive activity of some new substituted pyridazine derivatives. Journal of the Chilean Chemical Society. 2011;56(4):856-9.
16. Álvarez Y, Briones AM, Balfagón G, Alonso MJ, Salaices M. Hypertension increases the participation of vasoconstrictor prostanoids from cyclooxygenase-2 in phenylephrine responses. Journal of Hypertension. 2005;23(4):767-77.

17. Balaraman R, Hingorani N, Rathod SP. Studies on the anti hypertensive effect of abana in rats. Indian Journal of Pharmacology. 1993;25:209-14.

18. Russel A, watts S. Vascular reactivity of isolated thoracic aorta of the C57BL/6J mouse. Journal of pharmacology and Experimental Therapeutics. 2000;294(2):598-604

19. Edward ES, Field PF. Extracellular calcium and altered vascular responsiveness in the deoxycorticosterone acetate salt-treated rat. Journal of Hypertension. 1986;8(6):527-32.

20. Kwan CY, Graver AK. Membrane abnormalities occur in vascular smooth muscle but hot in non-vascular smooth muscle from rats with deoxycorticosterone-salt induced hypertension. Journal of Hypertension. 1983;1:257-26.

21. Palacios J, Vega JL, Parades A, Cifuentes F. Effect of phenylephrine and endothelium spontaneously hypertensive rats. Journal of Hypertension. 1998;31(6):1248-54.

22. Ożarowski M, Mikołajczak P, Kujawski R, Wielgus K, Klejewski A, Wolski H, et al. Pharmacological Effect of Quercetin in Hypertension and Its Potentia Application in Pregnancy-Induced Hypertension: Review of In Vitro, In Vivo, and Clinical Studies. Evidence-Based Complementary and Alternative Medicine. 2018:20(18):7421489-508

23. Larson AJ, Symons JD, Jalili T. Quercetin: A Treatment for Hypertension?-A Review of Efficacy and Mechanisms. Pharmaceuticals (Basel). 2010;3(1):237-50.

24. YingYang, Changwu Li, Xi Xiang, Zhaolai Dai, Jianyu Chang, Ming Zhang, et al. Ursolic acid prevents endoplasmic reticulum stress-mediated apoptosis induced by heat stress in mouse cardiac myocytes. Journal of Molecular and Cellular Cardiology. 2014;67:103-11.

\section{GRAPHICAL ABSTRACT}

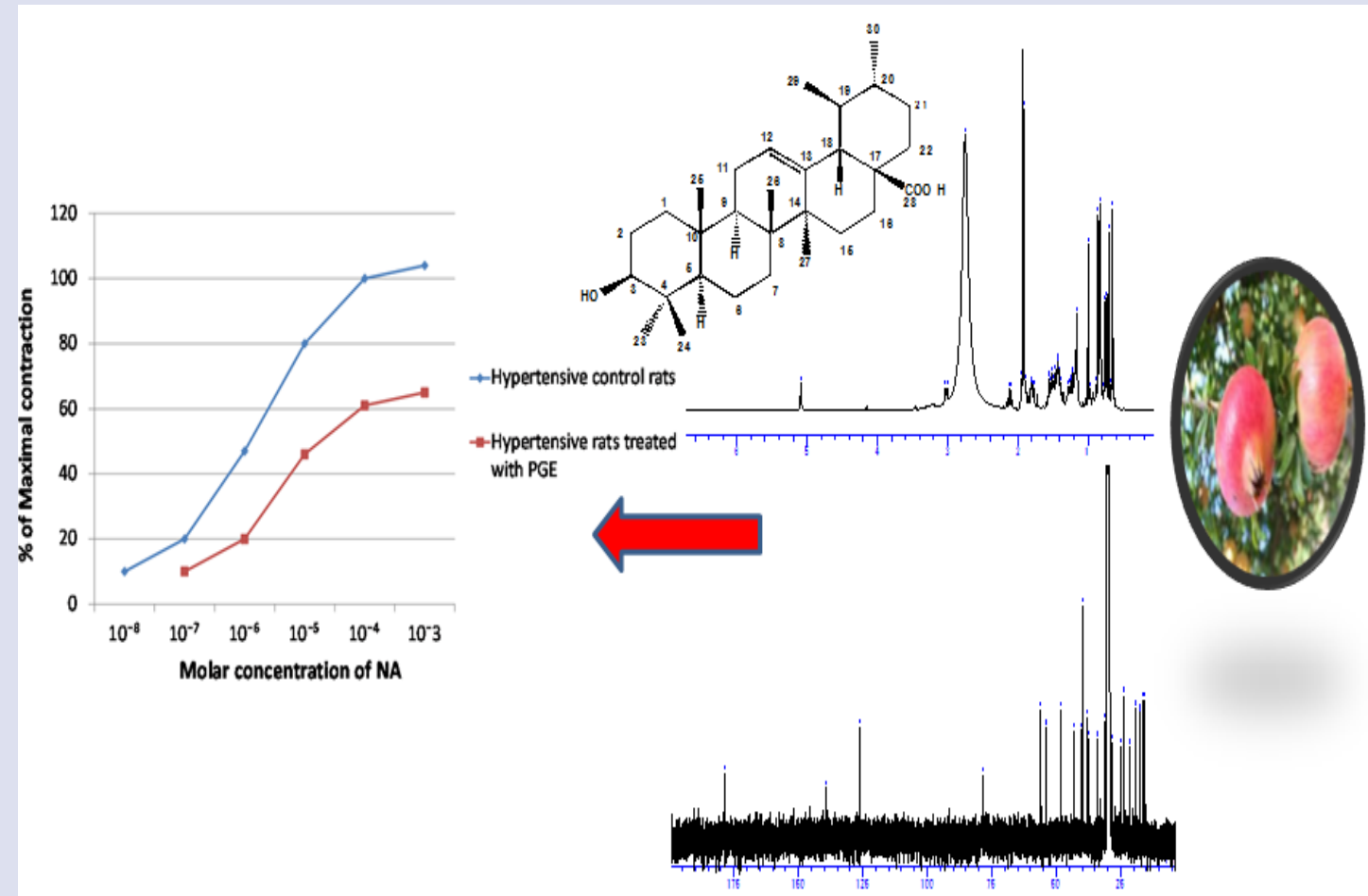




\section{ABOUT AUTHORS}

- Rafik Monir: Associate Professor, Pharmacognosy Department, Faculty of Pharmacy, Misr University for Science and Technology.

- Asmaa S. Abd Elkarim: Researcher, Chemistry of Tanning Materials and Leather Technology Department, National Research Centre.

- Mohamed Fouad Shalaby: Associate Professor, Pharmaceutical Sciences Department, Batterjee medical college for science and technology, Jeddah, Saudi Arabia.

- Alsayed Ahmed Zaki: Professor of Medical \& Clinical Pharmacology Department of Pharmacology, Faculty of Medicine.

- Samah Shabana: Associate Professor, Pharmacognosy Department, Faculty of Pharmacy, Misr University for Science and Technology.

Cite this article: Monir R, Elkarim ASB, Shalaby MF, Zaki AA, Shabana S. Anti-Hypertensive Activity of Punica granatum peels Ethyl Acetate Extract on Fludrocortisones Induced Hypertension in Wistar Rats. Pharmacogn J. 2020;12(5):1135-42. 